\title{
A Common Variant in PPP1R3 Associated With Insulin Resistance and Type 2 Diabetes
}

\author{
J ames Xia, Stephen W. Scherer, Patricia T.W. Cohen, Martin Majer, Tina Xi, Rodney A. Norman, \\ William C. Knowler, Clifton Bogardus, and Michal Prochazka
}

\begin{abstract}
Selected candidate genes have been analyzed in the Pima Indians of Arizona based on evidence that insulin resistance and type 2 diabetes have significant genetic determinants. An amino acid substitution at codon 905 of the glycogen-targeting subunit of type 1 protein phosphatase that regulates skeletal muscle glycogenesis was recently reported to be associated with changes in insulin action in Danish subjects. In addition to the variant at 905, we report here a novel substitution at codon 883 and common variant of an "ATTTA" element in the 3'-untranslated region (UTR) of the corresponding gene (PPP1R 3). The 3'-UTR variant resembled the mRNA-destabilizing AT(AU)-rich elements (AREs) and resulted in a 10-fold difference in reporter $M R N A$ halflife, was correlated with PPP $1 R 3$ transcript and protein concentrations in vivo, and was associated with insulin resistance and type 2 diabetes in the Pimas. The variant is more common in Pimas (0.56) than in Caucasians $(0.40)$. B ecause of its apparent effect on expression of PPP1R 3, it may, in part, contribute to the higher prevalence of type 2 diabetes in this Native American population. Dia betes 47:1519-1524, 1998
\end{abstract}

nsulin resistance (IR) is characterized by a reduced ability of insulin to mediate the uptake and metabolism of glucose by responsive tissues $(1,2)$. IR is a risk factor for type 2 diabetes, and there is strong evidence that compensatory hyperinsulinemia contributes to the pathogenesis of hypertension and dyslipidemia, predisposing to atherosclerosis, coronary heart disease, and stroke (3-6). Studies in various populations-including the Pima Indians of Arizona, who have the world's highest reported prevalence of type 2 diabetes-demonstrate that type 2 diabetes and IR have

From the Phoenix E pidemiology and Clinical Research B ranch (J .X., M.M., T.X., R.A.N., W.C.K., C.B., M.P.), National Institute of Diabetes and Digestive and Kidney Diseases, National Institutes of Health, Phoenix, Arizona; the Department of Genetics (S.W.S.), The Hospital for Sick Children, Toronto, Ontario, Canada; and Medical Research Council Protein Phosphorylation Unit (P.T.W.C.), Department of Biochemistry, University of Dundee, Dundee, U.K.

Address correspondence to Dr. Michal Prochazka, Phoenix E pidemiology and Clinical Research Branch, National Institute of Diabetes and Digestive and Kidney Diseases, National Institutes of Health, 4212 N. 16th St., Phoenix, AZ 85016. E-mail: mprochazka@phx.niddk.nih.gov. No reprints available.

Received for publication 13 May 1998 and accepted in revised form 2 J une 1998.

$A R E, A T(A U)$-rich element; G-subunit, glycogen-targeting subunit; IMGU, insulin-mediated glucose uptake; IR, insulin resistance; PCR, polymerase chain reaction; PP1G, glycogen-bound type 1 protein phosphatase; PPP1R3, gene encoding the glycogen-targeting subunit of type 1 protein phosphatase; RT, reverse transcription; UTR, untranslated region. significant heritable components (7-10). To identify the predisposing genes in the Pima Indians, we have analyzed selected candidate genes that regulate glucose storage as glycogen in skeletal muscle, because it is the main pathway of insulin-mediated glucose disposal in vivo $(11,12)$. Insulinresistant Pima Indians are characterized by decreased activity of skeletal muscle glycogen synthase as well as its regulatory enzyme, the glycogen-bound type 1 protein phosphatase (PP1G) (13-15). How ever, structural abnormalities have not been found in the gene encoding glycogen synthase (GYS1) (16) or the PP1 catalytic $\beta$-subunit (PPP1CB) (17). An amino acid polymorphism involving codon 905 (Asp905Tyr) of the glycogen-targeting subunit (G-subunit) of type 1 protein phosphatase was recently described to be associated with changes in insulin action in nondiabetic Danish Caucasians $(18,19)$. We have now investigated the corresponding gene (PPP1R3) in the Pima Indians.

\section{RESEARCH DESIGN AND METHODS}

Subjects. The participants were full-blooded Pima/Papago Indians of the Gila River Indian Community in Arizona who have been participating in a longitudinal study of the development of type 2 diabetes. A subset of nondiabetic subjects was recruited for inpatient studies to determine their insulin action and secretion. B riefly, these subjects were admitted to the clinical research center for 10-12 days and fed a weight-maintaining diet ( $50 \%$ carbohydrates; $30 \%$ fat; $20 \%$ proteins). Three or more days after admission, fasting plasma insul in and insulin-mediated glucose uptake (IMGU) rates were determined in response to low-dose (plasma insulin concentration $845 \pm 10 \mathrm{pmol} / \mathrm{l}$ ) and high-dose (plasma insulin concentration $12,210 \pm 185 \mathrm{pmol} / \mathrm{l})$ insulin by the two-step hyperinsulinemic-euglycemic clamp, as described (20). Insulin secretory function was assessed by an intravenous glucose tolerance test after an injection of $25 \mathrm{~g}$ glucose and in response to a 75 $\mathrm{g}$ oral glucose tolerance test. All parameters were adjusted for age, sex, and percent body fat determined by underwater weighing (20). For analysis, the person with the lowest BMI was selected from each nuclear family. If a person was examined more than once, data from his or her first visit was used. Characteristics of the subjects are summarized in Table 1 . All studies were approved by the Institutional Review Board of the National Institute of Diabetes and Digestive and Kidney Diseases and the Tribal Council of the Gila River Community, and each individual signed an informed consent form.

Chromosomal localization of PPP1R3. The position of PPP1R3 was initially determined by typing of somatic cell hybrids and subsequently refined by analysis of the radiation hybrid mapping set $\mathrm{RH}$ G3. Clones $701 \mathrm{~A} 8,742 \mathrm{~F} 8$, and $772 \mathrm{H} 4$ containing PPP1R3 as identified by polymerase chain reaction (PCR) screening of the CEPH YAC human genomic library were used to determine its organization. Transcript analysis. Transcript sizes and tissue distribution were determined with a human Multiple Tissue Northern blot from Clontech (Palo Alto, CA) hybridized with ${ }^{32} \mathrm{P}$-labeled probe spanning PPP1R3 coding sequence amplified by PCR from skeletal muscle cDNA. The alternatively spliced CDNA missing central part of exon 1 was PCR-amplified and sequenced in skeletal muscle cDNA from 24 Pima Indians and 1 Caucasian. The 3'-RACE experiment was performed using Marathon-Ready CDNA (Clontech) prepared from skeletal muscle poly-A ${ }^{+}$RNA. PCR products obtained by amplification with a PPP1R3-specific reverse primer and the AP 1 primer provided with the Marathon-Ready CDNA were cloned into the $\mathrm{PCR} 2.1$ vector using the TA cloning kit from Invitrogen (Carlsbad, CA) for subsequent sequencing. 
TABLE 1

Association of PPP1R3 polymorphisms with insulin action and diabetes

\begin{tabular}{|c|c|c|c|c|c|c|c|c|c|c|c|c|c|c|c|}
\hline \multirow[b]{2}{*}{ Genotypes } & \multicolumn{3}{|c|}{ ATTTA } & \multirow{2}{*}{\multicolumn{2}{|c|}{ P $\begin{array}{c}\text { Adjusted } \\
\text { P }\end{array}$}} & \multicolumn{3}{|c|}{883} & \multicolumn{2}{|r|}{ Adjusted } & \multicolumn{3}{|c|}{905} & \multicolumn{2}{|r|}{ Adjusted } \\
\hline & 11 & 12 & 22 & & & Ser/Ser & Ser/Arg & Arg/Arg & $\mathrm{P}$ & $\mathrm{P}$ & Tyr/Tyr & Asp/tyr & Asp/Asp & $\mathrm{P}$ & $\mathrm{P}$ \\
\hline \multicolumn{16}{|l|}{ Insulin action } \\
\hline $\mathrm{M} / \mathrm{W}$ & $14 / 6$ & $44 / 17$ & $22 / 11$ & - & - & $6 / 1$ & $35 / 15$ & $38 / 19$ & - & - & $13 / 6$ & $46 / 18$ & $22 / 10$ & - & - \\
\hline Age (years) & $29 \pm 8$ & $27 \pm 6$ & $27 \pm 6$ & NS & NS & $30 \pm 7$ & $28 \pm 6$ & $27 \pm 6$ & NS & NS & $28 \pm 8$ & $28 \pm 6$ & $27 \pm 6$ & NS & NS \\
\hline Body fat (\%) & $30 \pm 9$ & $30 \pm 9$ & $31 \pm 9$ & NS & NS & $30 \pm 10$ & $30 \pm 9$ & $30 \pm 8$ & NS & NS & $30 \pm 9$ & $30 \pm 8$ & $31 \pm 9$ & NS & NS \\
\hline $\begin{array}{c}\log _{10} \text { fasting } \\
(\mathrm{pmol} / \mathrm{l})\end{array}$ & $1.4 \pm 0.2$ & $1.5 \pm 0.2$ & $1.5 \pm 0.2$ & 0.07 & $<0.01$ & $1.3 \pm 0.2$ & $1.5 \pm 0.2$ & $1.5 \pm 0.2$ & 0.05 & $<0.01$ & $1.4 \pm 0.2$ & $1.5 \pm 0.2$ & $1.5 \pm 0.2$ & 0.05 & $<<0.02$ \\
\hline $\begin{array}{l}\text { IMGU to } \\
\text { low-dose insulin } \\
\text { (mg/kg EMBS } \cdot \mathrm{m}\end{array}$ & $3.46 \pm 1.49$ & $2.65 \pm 0.99$ & $2.60 \pm 0.88$ & 0.01 & $<0.01$ & $4.24 \pm 1.74$ & $2.64 \pm 0.89$ & $2.72 \pm 1.05$ & $<0.01$ & $<0.01$ & $3.43 \pm 1.47$ & $2.61 \pm 0.93$ & $2.69 \pm 0.98$ & $<<0.02$ & $<0.01$ \\
\hline $\begin{array}{l}\text { IMGU to } \\
\text { high-dose insulin } \\
\text { (mg/kg EMBS } \cdot \mathrm{m}\end{array}$ & $9.71 \pm 2.14$ & $8.20 \pm 2.27$ & $8.65 \pm 2.11$ & $<0.04$ & 0.01 & $11.01 \pm 1.64$ & $8.27 \pm 2.24$ & $8.52 \pm 2.22$ & 0.01 & $<0.01$ & $9.60 \pm 2.40$ & $8.19 \pm 2.13$ & $8.85 \pm 2.21$ & $<0.04$ & $<0.03$ \\
\hline \multicolumn{16}{|l|}{ Diabetes } \\
\hline $\mathrm{M} / \mathrm{W}$ & $84 / 98$ & $189 / 261$ & $123 / 175$ & - & - & $29 / 40$ & $170 / 212$ & $197 / 282$ & - & - & $87 / 102$ & $189 / 259$ & $120 / 173$ & - & - \\
\hline Age (years) & $44 \pm 14$ & $43 \pm 14$ & $46 \pm 15$ & NS & NS & $45 \pm 14$ & $43 \pm 15$ & $45 \pm 15$ & NS & NS & $44 \pm 14$ & $43 \pm 14$ & $46 \pm 15$ & NS & NS \\
\hline BMI $\left(\mathrm{kg} / \mathrm{m}^{2}\right)$ & $33.9 \pm 8.4$ & $34.1 \pm 8.1$ & $33.3 \pm 7.7$ & NS & NS & $33.9 \pm 8.7$ & $34.1 \pm 8.2$ & $33.6 \pm 7.8$ & NS & NS & $34.3 \pm 8.5$ & $33.9 \pm 8.1$ & $33.3 \pm 7.7$ & NS & NS \\
\hline Prevalance (\%) & 56 & 64 & 69 & $<0.02$ & $<0.04$ & 57 & 60 & 68 & $<0.02$ & $<0.05$ & 56 & 64 & 69 & $<0.01$ & $<0.04$ \\
\hline
\end{tabular}

The data (means $\pm S D$ ) of fasting insulin and of low-dose and high-dose IMGU rates were analyzed by multiple regression analysis. Differences in prevalence of type 2 diabetes with onset age $<45$ years in 930 people were analyzed by the $\chi^{2}$ method. $P=P$ values for statistical comparison of unadjusted parameters. Adjusted $P=P$ values for comparison of parameters adjusted for sex, age, percent body fat, or BMI. EMBS, estimated metabolic body size (33).

Genomic DNA analysis. Genomic DNA was prepared from white blood cells or transformed lymphoblasts after signed informed consent was obtained from the participants. Southern blot analysis was performed with EcoRI-digested genomic DNA. Coding sequences, splicing sites, and the $5^{\prime}$ - and 3 '-untranslated regions (UTRs) were screened for mutations in 30 nondiabetic Pima Indians by PCR, and the products were sequenced with nested primers using the Dye terminator cycle sequencing $\mathrm{FS}$ kit and the $\mathrm{ABI}$ automated sequencer model 373A from $\mathrm{ABI}$ Division of Perkin Elmer (Foster City, CA). Primer information is available upon request. Genotyping of polymorphisms at codon $\mathbf{8 8 3}, \mathbf{9 0 5}$, and ARE. The Ddel variant at codon 905 was genotyped on PCR products amplified with the forward primer $5^{\prime}$-TAGGTATTTGTAATGTACGTGTA-3' and the reverse primer $5^{\prime}$ GTAACTGCATTCTCTACAGCAA-3'. The ARE variant was genotyped using primers $5^{\prime}$-CAGATAAAACATGGACAATGGC- $3^{\prime}$ and $5^{\prime}$-TTGAAATATTTGATCAATGAATCC-3'. The variant at codon 883 was genotyped using the mismatchPCR/RFLP assay (21). We designed a reverse primer that lies immediately adjacent to the variant site and incorporates a single base mismatch (indicated in lower case " $g$ " instead of " $T$ ") at the second base preceding its 3 ' end ( 5 'TTTCTTTGATAATTCTTGAACCgG-3'). PCR was performed in combination with a perfectly matched upstream forward primer ( 5 '-TAGGTATTTGTAATGTACGTGTA-3') to produce a 254-bp fragment. In the presence of a " $\mathrm{C}$ " at the polymorphic site immediately adjacent to the $3^{\prime}$ end of the mismatched primer, the PCR product gained an artificial Haell restriction site ( $g G C C)$, whereas DNA amplified from an allele containing an " $A$ " at this position ( $\mathrm{GGAC}$ ) remained uncleaved. All polymorphisms were resolved by electrophoresis on a $4 \%$ agarose gel.

Analysis of RNA and protein from skeletal muscle biopsies. Collection of skeletal muscle biopsies and preparation of RNA and protein extracts were described previously (16). In Northern analysis, $20 \mathrm{mg}$ total RNA was fractionated by electrophoresis through a $1.2 \%$ formaldehyde-agarose gel, transferred to a nitrocellulose membrane, and hybridized with radiolabeled cDNA probes. OligodT primed CDNA was synthesized from $2 \mu \mathrm{g}$ of total RNA using the Superscript CDNA Synthesis Kit from GIBCO BRL (Gaithersburg, MD). All primer combinations for $\mathrm{mRNA} / \mathrm{cDNA}$ quantification were designed to span at least one intron in the gene to avoid co-amplification of genomic DNA that may contaminate RNA preparations. $\beta$-Actin served as an internal control, as described (16). Differences in expression between transcripts containing ARE alleles 1 and 2 in heterozygotes were assessed by simultaneously comparing the relative allelic ratio in genomic DNA and skeletal muscle cDNA from each individual. PCR was performed using ${ }^{32}$ P-labeled forward primer ( $5^{\prime}$-CAGATAAAACATGGACAATGGC- ${ }^{\prime}$ ) and unlabeled reverse primer (5'-TTGAAATATTTGATCAATGAATCC- $\left.3^{\prime}\right)$, and products were resolved on a $6 \%$ sequencing gel. After 24 cycles, al iquots were collected every two to three subsequent cycles to determine when the amplification was in an exponential phase. G-Subunit protein was detected by Western blotting using a polyclonal rabbit antibody (diluted 1:400) developed against a synthetic peptide encompassing amino acids 391-407 from Research Genetics (Huntsville, $A L$ ), followed by treatment with a secondary anti-rabbit Ig heavy chain antibody (diluted 1:15,000) from Pierce (Rockford, IL). Variation in loading between lanes was normalized by immunostaining of the blots with a mouse monoclonal antibody against human $\alpha$-actin (diluted 1:500) from Sigma (St. Louis, MO), followed by a secondary anti-mouse antibody (diluted 1:15,000; Pierce). The blots were stained with the SuperSignal chemiluminescent substrate (Pierce), and films were exposed for different time periods.

Analysis of reporter mRNA. The reporter constructs were created by inserting a 860-bp fragment of PPP1R3 3'-UTR encompassing ARE allele 1 or allele 2 between the stop codon and the first polyadenylation site of the rabbit $\beta$-globin gene in vector pNEOR $\beta G^{G C}(22)$. The allelic fragments were PCR-amplified with primers introducing an artificial Xbal site at both ends, and the products were ligated into a unique Xbal site within the $3^{\prime}$-UTR of the $\beta$-globin reporter gene. Constructs containing allele ARE 1 and ARE 2 in the forward $(F)$ and reverse $(R)$ orientations designated pR3ARE $1 F, p R 3 A R E 2 F, p R 3 A R E 1 R$, and pR3ARE $2 R$, respectively, were identified by PCR and verified by sequencing. NIH3T3 cells were grown in Dulbecco's modified eagle medium (GIBCO BRL) supplemented with $10 \%$ fetal bovine serum, $50 \mathrm{U} / \mathrm{ml}$ penicillin $\mathrm{G}$ and $50 \mu \mathrm{g} / \mathrm{ml}$ streptomycin. Cells were seeded at density $2 \times 10^{6}$ into $60 \mathrm{~mm}$ Petri dishes and incubated for $24 \mathrm{~h}$, reaching approximately $50 \%$ confluency. Transfections were performed using 4- $\mu \mathrm{g}$ plasmid DNA and CalPhos Maximizer Transfection Kit (Clontech), and poly- $A^{+}$RNA was isolated with Oligotex Direct mRNA Kit from QIAGEN (Valencia, CA) after 24 and $48 \mathrm{~h}$. To determine the half-life of the reporter RNA, cells were treated with actinomycin D $(5 \mu \mathrm{g} / \mathrm{ml})$, and RNA was extracted at different time points over the 24-h period after transfection. Reporter transcripts were quantified by reverse transcription (RT)-PCR using neo mRNA/CDNA as an internal control.

All measurements of PPP1R3 transcript, G-subunit protein, and reporter mRNA were performed in triplicate. The coefficients of variation were 15, 11, and $6 \%$, respectively.

Statistical analysis. Statistical comparison of quantitative traits were performed using the general linear modeling program of the SAS Institute (Cary, NC). In these analyses, genotype was treated as a class variable. Plasma insulin concentrations were $\log _{10}$ transformed before analysis to approximate a normal distribution. Repeated measures of analysis of variance and $t$ tests were also performed for quantitative comparisons of PPP1R3 and reporter mRNA levels.

\section{RE SULTS}

We have determined that PPP1R3 is located on chromosome 7q31.1-q31.2 and consists of four exons (Fig. 1A). Northern blot hybridization revealed two transcripts $(\sim 5 \mathrm{~kb}$ 


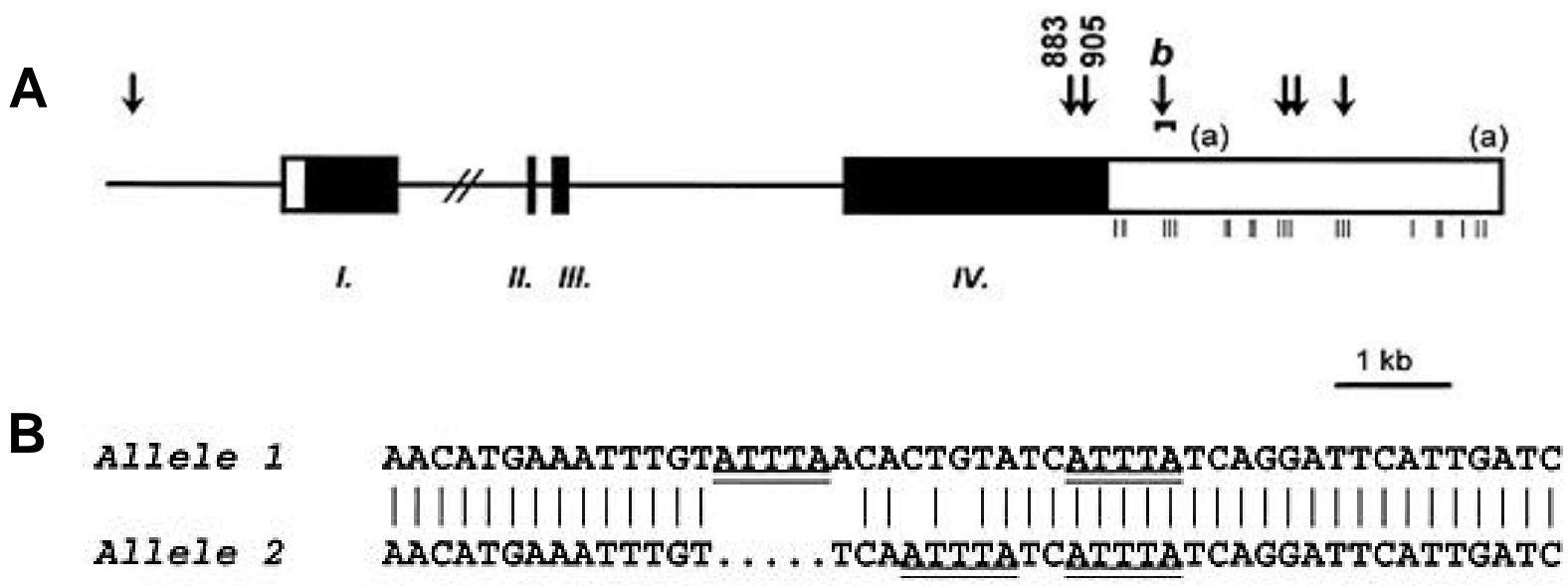

FIG. 1. Genomic structure of PPP1R3. A: Coding sequences are shown as solid boxes, 5'- and $3^{\prime}$-UTR as open boxes, and introns as thin lines. Two polyadenylation sites (each preceded by the characteristic AATAAA signal) are marked by (a), and ARE motifs in 3'-UTR by vertical tick marks. All variants are indicated by arrows. The Arg883Ser and A sp905Tyr variants are determined by an AGG $\rightarrow$ AGT and GAC $\rightarrow$ TAC substitution, respectively. The polymorphic ARE is indicated by $b$. B: Alignment of ARE allele 1 and 2 encompassing the third and fourth ATTTA element (double underlined) in 3'-UTR. Due to a small rearrangement, the distance between both elements is 10 bp in allele 1 and 2 bp in allele 2. GenBank accession numbers: AF 024576-AF 024579.

and $\sim 7.5 \mathrm{~kb}$ ) in human skeletal muscle and heart that differ by the length of the $3^{\prime}$-UTR as detected by $3^{\prime}$-RACE. In skeletal muscle, the 5-kb transcript was about 2.5-fold more abundant than the 7.5-kb transcript. We also found a shorter transcript missing 521 bp of the coding sequence between bases 179 and 699 of the published CDNA (23). The beginning and end of the excluded segment are demarcated by the characteristic splice donor (GT) and splice acceptor (AG) sites, respectively, and we conclude that the shorter $\mathrm{mRNA}$ is produced by alternative splicing. This form, representing 8-24\% of the full-length transcript, has a change in reading frame and predicts a truncated protein consisting of 74 amino acids. However, it is not yet known whether this shorter transcript is translated.

Southern blot analysis of EcoRI-digested DNA from 52 nondiabetic Pimas did not show any major structural alterations in PPP1R3, regardless of whether the subjects were insulin sensitive or insulin resistant. Screening of the gene by PCR and sequencing in 30 nondiabetic individuals revealed two single-base substitutions within the last exon that predict an aspartic acid-to-tyrosine variant at codon 905 (Asp905Tyr), as previously described in Caucasians (18), and a novel arginine-to-serine variant at codon 883 (Arg883Ser). Four single-base substitutions were identified in noncoding regions, including one approximately $1.6 \mathrm{~kb}$ upstream from the starting methionine codon, and three variants within a 600bp region downstream from the first polyadenylation signal (Fig. 1A). There was also a 5-bp length polymorphism in $3^{\prime}$ UTR affecting the distance between two ATTTA pentanucleotides (alleles ARE 1 and ARE 2; Fig. 1B) that are the smallest consensus motifs of mRNA-destabilizing AREs (24). All polymorphisms were in linkage disequilibrium, and we have genotyped the di-allelic variants at codons 883 and 905, as well as ARE, in 930 Pima Indians. The frequencies of Ser883, Tyr905, and ARE 1 were 0.27, 0.44, and 0.44, respectively; each was associated with a lower fasting plasma insulin, higher IMGU in response to low-dose and high-dose insulin infusions, and lower prevalence of type 2 diabetes than alleles Arg883, Asp905, and ARE 2 (Table 1). The differences remained statistically significant $(<0.05)$ after adjusting for sex, age, and BMI or percent body fat individually, as well as for all covariates combined.

By analysis of DNA from 56 CEPH Caucasians, we found that the ARE polymorphism was also common in this population. However, the frequency of the ARE2 allele (0.4) was significantly lower than in the Pimas $(P<0.001)$. F urthermore, codon 883 polymorphism was not observed in this Caucasian sample.

In skeletal muscle biopsies from 20 nondiabetic Pima Indians, there was a sixfold interindividual variation of PPP1R3 mRNA concentration that positively correlated with differences in G-subunit protein concentration ( $r=0.73$; $P<0.01$; Fig. 2A). Moreover, the mRNA and protein correlated positively with IMGU in response to high-dose insulin ( $r=0.51$, $P=0.02$; Fig. $2 B$ and $C$ ). ARE motifs have been implicated in posttranscriptional regulation of mRNA stability in some genes (24); and the mean PPP1R3 mRNA concentration in skeletal muscle from nine ARE 2/ARE 2 homozygous individuals was 44\% lower compared with that from four ARE 1/ARE 1 homozygotes ( $P=0.01 ; F i g .2 D)$. The quantitative differences between the ARE 1- and ARE2-containing PPP1R3 mRNA were further confirmed in 12 ARE 1/ARE 2 heterozygotes in whom the ARE2-containing MRNA had an approximately $20 \%$ lower concentration relative to the ARE 1containing mRNA ( $P<0.001$; not show $n$ ).

To determine whether the PPP1R3 mRNA differences observed in skeletal muscle biopsies could be attributed to the polymorphic 3'-UTR, we constructed plasmids in which 860 bp betw een the stop codon and the first polyadenylation site of PPP1R3 (encompassing ARE 1 and ARE 2 alleles, respectively) were inserted in either orientation downstream of the stop codon in the $3^{\prime}$-UTR of rabbit $\beta$-globin reporter gene in the vector pNEOR $\beta G^{\mathrm{GC}}(22)$ (Fig. 3A). The abundance of the chimeric $\beta$-globin transcript was measured $24 \mathrm{~h}$ and $48 \mathrm{~h}$ after transfection, and no significant differences in $\beta$-globin mRNA levels were observed between cells transfected with pNEOR $\beta G^{\mathrm{GC}}$ vector alone and those transfected with constructs containing the 860-bp PPP1R3 fragment in reverse ori- 

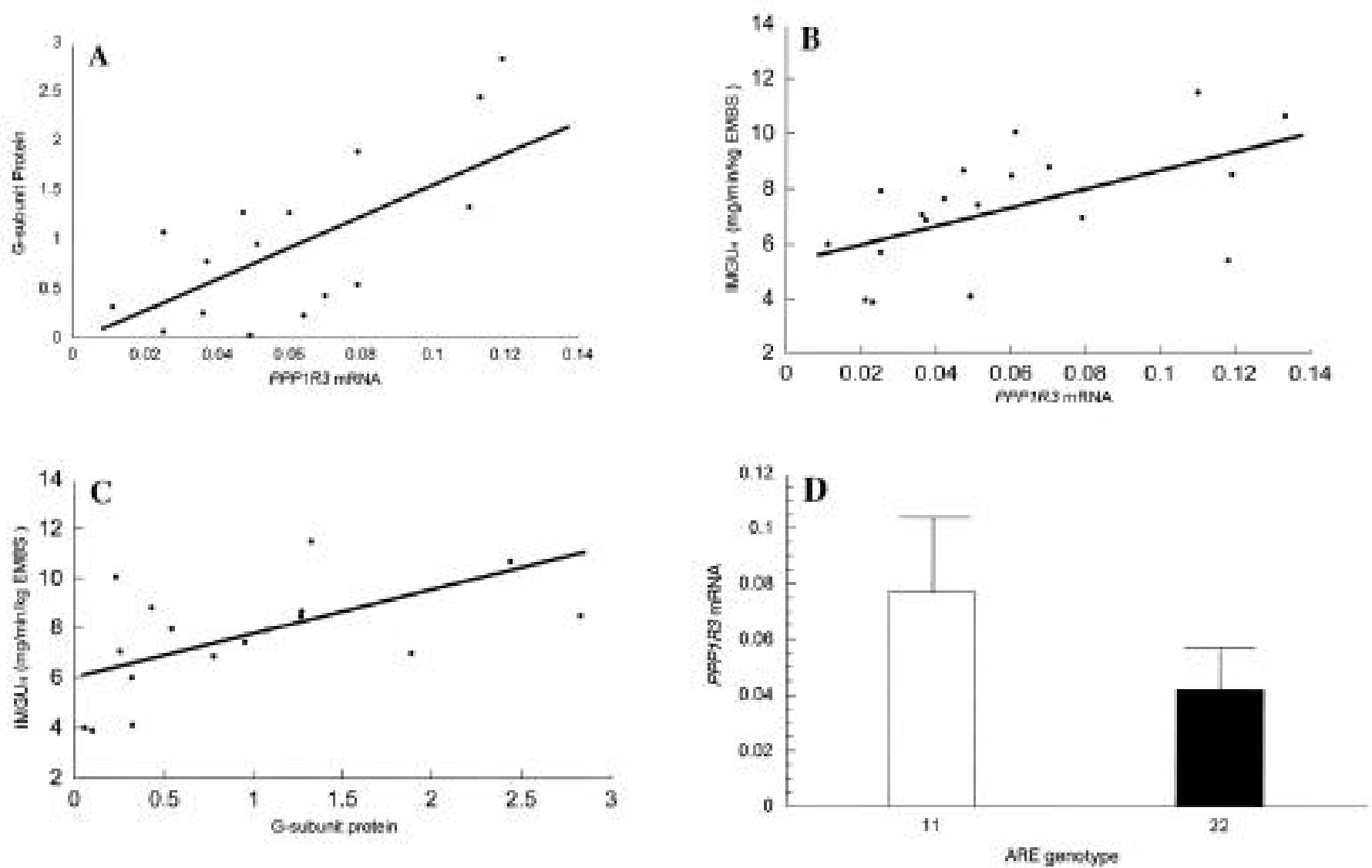

FIG. 2. PPP1R 3 mRNA and G-subunit protein levels in skeletal muscle. A: Correlation between levels of PPP1R 3 mRNA and G-subunit protein $(r=0.73, P<0.01)$. Correlation between PPP1R3 mRNA (B) $(r=0.51, P=0.02)$ or G-subunit protein $(C)(r=0.51, P=0.02)$ and IMGU in response to a high dose of insulin $(15,744 \pm 1,482 \mathrm{pmol} / \mathrm{l})$ measured by the hyperinsulinemic-euglycemic clamp (20). $D$ : Concentration of mR $\mathrm{mA}$ in homozygotes for ARE allele $\mathbf{1}$ versus allele $\mathbf{2}(\mathbf{P}=\mathbf{0 . 0 1}$ ). The relative $\mathrm{mRNA}$ concentration (PPP1R $\mathbf{3} / \mathbf{\beta}$-actin mRNA ratio) determined by $R T$ $P C R$ is the mean of triplicate measurements, and protein levels were measured by Western blots.

entation ( $p R 3 A R E 1 R$ and pR 3ARE 2R; Fig. 3B). However, the relative abundance of reporter mRNA encoded by constructs containing the 860-bp fragment in forward orientation ( $p R 3 A R E 1 F$ and pR3ARE 2F) was approximately sevenfold lower than that observed with pR3ARE 1R, pR3ARE 2R, and pNEOR $\beta G^{G C}$ alone. Furthermore, the reporter mRNA encoded by pR3ARE $2 F$ was $20-40 \%$ lower than that observed for PR3ARE 1F $24 \mathrm{~h}$ and $48 \mathrm{~h}$ after transfection ( $\mathrm{P}<0.01$; Fig. $3 B)$. The decay rates of all transcripts were also measured during a 24-h period after treatment with the transcription inhibitor actinomycin D. No significant differences in $\beta$-globin mRNA were observed with $p R 3 A R E 1 R$, $p R 3 A R E 2 R$, and pNEOR $\beta G^{G C}$, whereas a 47 and $84 \%$ decrease was observed with $p R 3 A R E 1 F$ and $p R 3 A R E 2 F$, respectively $(P<0.001$; Fig. 3B). The estimated apparent half-life of the chimeric $\beta$-globin mRNA containing ARE 2 was at least 10-fold shorter than that observed for mRNA with ARE1 ( $~ 2 \mathrm{~h}$ vs. $>24 \mathrm{~h}$, respectively; $\mathrm{P}<0.001$; Fig. 3C).

\section{DISCUSSION}

We have investigated PPP1R3 as a functional candidate gene that could contribute to IR and type 2 diabetes in the Pima Indians. We describe here several variants in this gene that are associated with parameters of insulin action and with differences in diabetes prevalence. During the progress of this study, we have completed a genome-wide linkage scan of microsatellite markers in this population. Analysis of affected sib-pairs revealed that the location of markers showing an evidence for potential linkage with type 2 diabetes on chromosome 7 coincides with the genetic location of $\operatorname{PPP1R3}(25,26)$. The finding of linkage with diabetes in this region lends additional support to the hypothesis that variants in the PPP1R3 gene contribute to the etiology of type 2 diabetes.

The associated polymorphisms we detected in PPP1R3 include a potential MRNA destabilizing ARE motif in the $3^{\prime}-$ UTR. ARE motifs in 3'-UTR have been implicated in mRNA degradation $(22,24,27,28)$. The $7.5-\mathrm{kb}$ transcript of PPP1R3 contains 21 ARE motifs that may explain the $\sim 2.5$-fold lower abundance in muscle compared with the 5-kb mRNA, which has 5 motifs. In addition to their number, the relative spacing of AREs and base composition of the surrounding sequences play an important role in establishing their function as destabilizing elements (24). For example, it has been demonstrated that a transcript containing four clustered ATTTA elements was rapidly degraded, whereas an analogous transcript with four scattered AREs was stable (29). The ARE polymorphism of PPP1R3 changes spacing between the third and fourth motif and may affect mRNA stability. The halflife of the natural PPP1R3 mRNA has not been reported yet, and we attempted to measure it in skeletal muscle-derived 
A

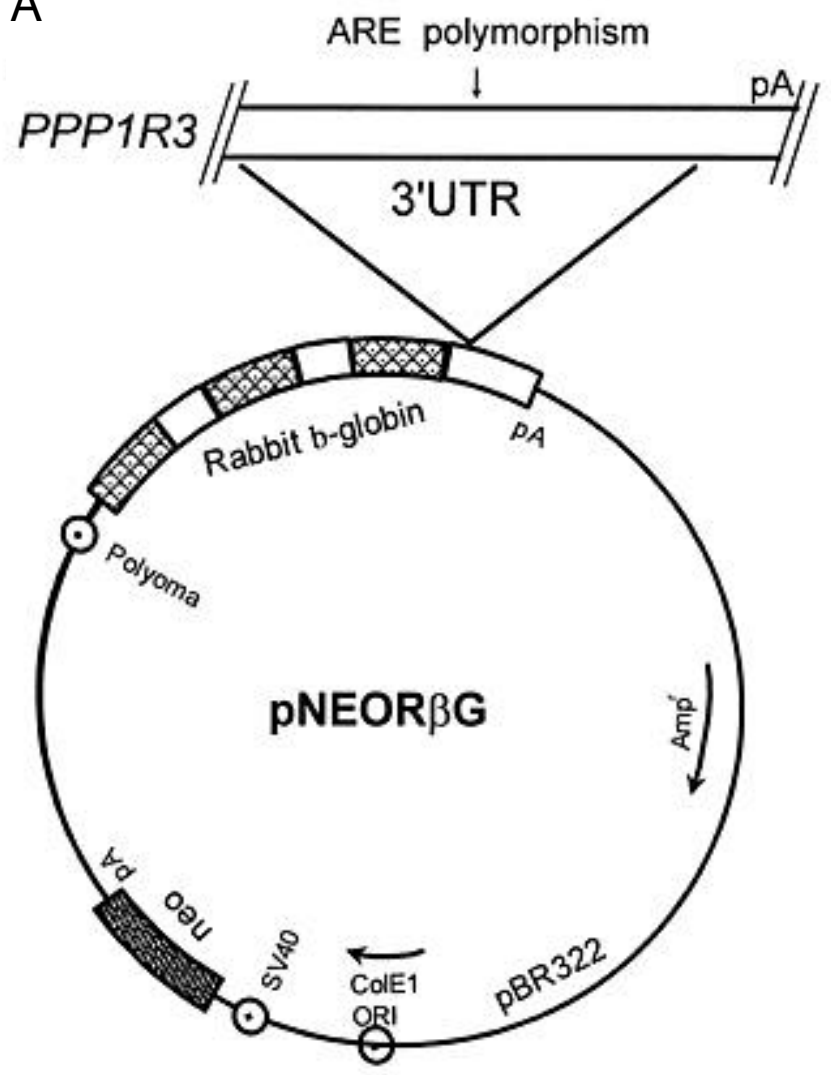

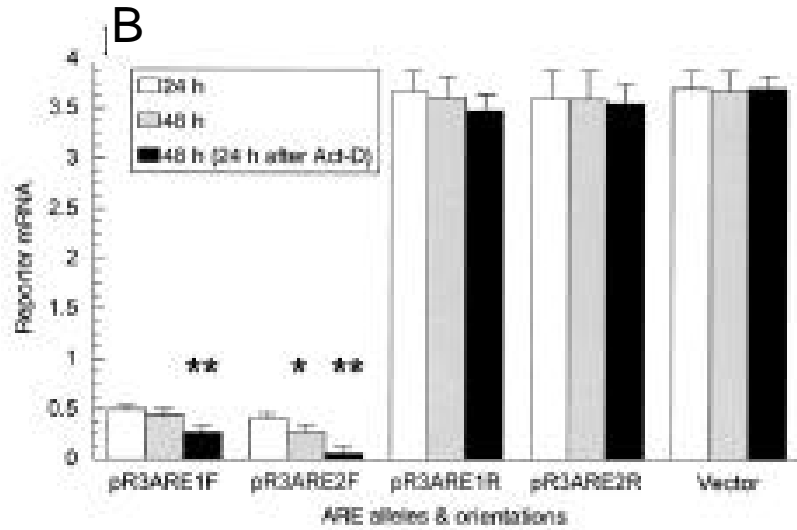

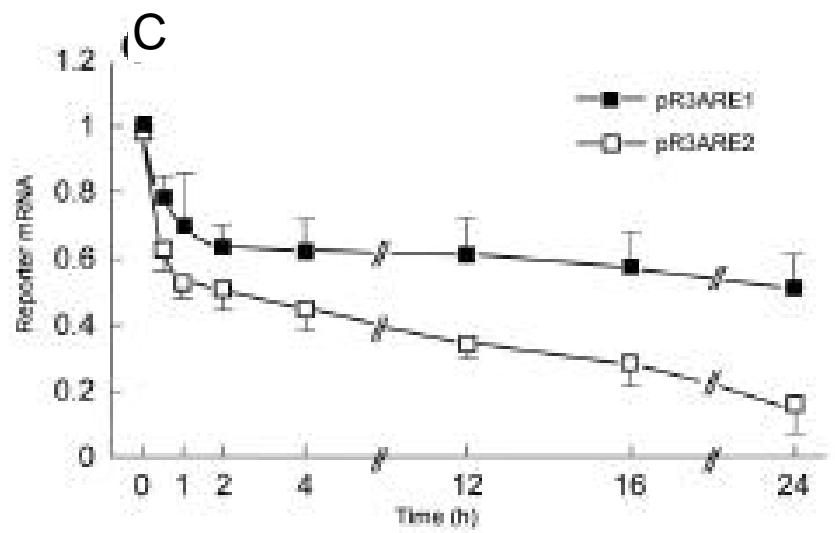

FIG. 3. Expression of ARE-containing reporter constructs in NIH 3 T 3 cells. A: Reporter constructs were created by inserting 860 bp of $3^{\prime}-$ UTR segments encompassing PPP1R 3 ARE allele 1 or allele 2 in either the forward (F) or reverse (R) orientation in the $3^{\prime}$-UT R of rabbit $\beta$-globin reporter gene in PNE OR G $^{\mathrm{GC}}$. The constructs were designated PR3ARE 1F, pR3ARE 1R, PR3ARE 2F, and pR 3ARE 2R, respectively. B: Reporter mRNA expression in NIH3T 3 cells was measured 24 and $48 \mathrm{~h}$ after transfection without or with actinomycin D (Act-D) added $24 \mathrm{~h}$ after transfection. Statistically significant differences of the measurements (mean \pm SD) between pR3ARE $1 F$ and $p R 3 A R E 2 F$ determined by the $t$ test are indicated $(* \mathrm{P}<0.01, * * \mathrm{P}<0.001)$. C: Time-dependent degradation of reporter mRNA in cells treated with actinomycin $\mathrm{D} 24 \mathrm{~h}$ after transfection. Data (mean \pm SD) from three different experiments were used to test differences between ARE 1- and ARE 2-containing reporter transcripts by repeated measures of analysis of variance $(P<0.001)$.

human cell lines. However, we were unable to detect the transcript by RT-PCR in RNA extracted from three different primary myoblast cell cultures derived from nondiabetic Pima Indians (30) or in the rhabdomyosarcoma cell line A204. In contrast, the control $\beta$-actin transcript was abundantly expressed in these cells (not shown). Nevertheless, our data obtained with the chimeric $\beta$-globin constructs demonstrate that the 3'-UTR segment encompasses mRNA destabilizing signals, which act in an orientation-dependent manner, and that the polymorphic ARE further modulates the steady-state level of chimeric $\beta$-globin reporter transcripts. The $20-44 \%$ reduction in the abundance of ARE2-containing mRNA found in skeletal muscle of both homozygotes and heterozygotes for ARE 1 and ARE 2 alleles is consistent with the differences in the steady-state reporter mRNA concentration observed between $p R 3 A R E 1 F$ and $p R 3 A R E 2 F$.

Chen et al. (23) also reported up to fivefold variation in the abundance of PPP1R3 mRNA in Danish Caucasians, but no significant differences were found between 15 diabetic and 14 control subjects. We have found that the frequency of the ARE 1 and ARE 2 alleles in a group of 56 CE PH Caucasians was 0.60 and 0.40 , respectively, which demonstrates that this ARE polymorphism is not unique to the Pima Indian population. Genotyping of this polymorphism in a large number of subjects will be necessary to assess its cor- relation with mRNA differences and with type 2 diabetes in the Danish and in other populations. In our study, we limited the quantitative analysis of PPPIR3 mRNA to nondiabetic subjects to avoid potentially misleading secondary changes in the expression in skeletal muscle of diabetic subjects. Furthermore, based on our data, we do not believe that the large interindividual variability of the transcript concentration is attributable only to the ARE variant. Rather, this polymorphism modulates the mRNA level, and other genetic as well as nongenetic factors are likely to contribute to the variation between subjects.

Similar to our findings of differences in insulin action in vivo second to changes in PP1G levels, Ragolia and Begum (31) recently reported that the overexpression of this subunit in rat skeletal muscle cells resulted in increased insulin-stimulated glucose uptake rates, glycogen synthase activation, and rates of glycogen synthesis. Also, the Tyr905 encoding allele has been recently associated with an increased insulin sensitivity in obese Caucasian males, although no effect on type 2 diabetes prevalence was observed (19). From our current data, we cannot determine whether the ARE polymorphism alone accounts for the observed associations in the Pimas. The functional consequences of the Asp905Tyr and Arg883Ser substitutions, if any, are yet unknown, and relevant studies are still in progress to investigate their biological 
effects. Because we found an association of insulin resistance and diabetes with a polymorphism of an mRNA-destabilizing element that genetically and functionally correlates with quantitative differences in PPP1R3 expression, it appears more likely that this variant largely contributes to the association of PPP1R3 with insulin resistance and diabetes. Nevertheless, it is also formally possible that the polymorphisms in PPP1R3 represent markers for yet another susceptibility gene in this region that could be the basis for the observed associations.

Insulin-mediated glucose disposal rate varies considerably, even among subjects with normal glucose tolerance $(1,3)$. It has been estimated that $38-49 \%$ of the variance in insulin action in the Pima Indians is heritable (32), and the polymorphisms at PPP1R3 therefore do not account for all of the heritability in this population. We anticipate that additional genes contribute to the manifestation of IR that predisposes to type 2 diabetes in the Pima Indians. The discovery that the ARE 2 allele contributes to impaired insulin action and hyperinsulinemia, and the high frequency of this allele in Caucasians, indicates that this common variant may have a broader significance, contributing to IR and type 2 diabetes in various populations.

\section{ACKNOWLE DG ME NTS}

We thank the members of the Gila River Indian Community for their cooperation in the clinical studies, the nursing staff for their professional care of the volunteers, D. Nickle and N. Riebow for expert technical assistance, S. Kobes for help with statistical analysis, Dr. G. Shaw for providing pNEOR $\beta G^{G C}$, Dr. P. Permana for providing antibody against G-subunit, and Dr. Y.H. Chen for initial studies on the chromosomal location.

\section{REFERE NCES}

1. Reaven GM: Pathophysiology of insulin resistance in human disease. Physi ol Rev 75:473-486, 1995

2. Reaven GM: Role of insulin resistance in human disease. Diabetes 37:1959-1967, 1988

3. Reaven GM, Lithell H, Landsberg L: Hypertension and associated metabolic abnormalities: the role of insulin resistance and the sympathoadrenal system. N Engl J Med 334:374-381, 1996

4. Bressler $P$, Baile SR, Matsuda M, DeF ronzo RA: Insulin resistance and coronary artery disease. Di abetologi a 39:1345-1350, 1996

5. Hong Y, Pedersen NL, Brismar K, de Faire U: Genetic and environmental architecture of the features of the insulin-resistance syndrome. Am J Hum Genet 60:143-152, 1997

6. Bogardus C: Insulin resistance in the pathogenesis of NIDDM in Pima Indians. Di abetes Care16:228-231, 1993

7. Bogardus C, Lillioja S: Pima Indians as a model to study the genetics of NIDDM. J Cell Bi ochem 48:337-343, 1992

8. Schumacher MC, Hasstedt SJ , Hunt SC, Williams RR, Elbein SC: Major gene effect for insulin levels in familial NIDDM pedigrees. Di abetes 41:416-423, 1992

9. Hanis CL, Boerwinkle E, Chakraborty R, Ellsworth DL, Concannon P, Stirling $B$, Morrison VA, Wapelhorst B, Spielman RS, Gogolin-E wens KJ , Shepard J M, Williams SR, Risch N, Hinds D, Iwasaki N, Ogata M, Omari Y, P etzold C, Rietzch H, Schroder HE, Schulze J, Cos NJ, Menzel S, Boriraj VV, Chen X: A genome-wide search for human non-insulin-dependent (type 2) diabetes genes reveals a major susceptibility locus on chromosome 2. Nat Genet 13:161-166, 1996

10. Mahtani MM, Widen $E$, Lehto $M$, Thomas J , McCarthy M, Brayer J , Bryant B, Chan G, Daly M, Forsblom C, Kanninen T, Kirby A, Kruglyak L, Munnelly K, Parkkonen M, Reeve-Daly MP, Weaver A, Brettin T, Duyk G, Lander ES, Groop LC: Mapping of a gene for type 2 diabetes associated with an insulin secretion defect by a genome scan in Finnish families. Nat Genet 14:90-94, 1996

11. Young AA, Bogardus C, Wolfe-Lopez D, Mott DM: Muscle glycogen synthesis and disposition of infused glucose in humans with reduced rates of insulinmediated carbohydrate storage. Di abetes 37:303-308, 1988

12. Bogardus C, Lillioja S: Where all the glucose doesn't go in non-insulin-dependent diabetes mellitus. N Engl J Med 322:262-263, 1990

13. Freymond D, Bogardus C, Okubo M, Stone K, Mott DM: Impaired insulinstimulated muscle glycogen synthase activation in vivo in man is related to low fasting glycogen synthase phosphatase activity.J Clin Invest 82:1503-1509, 1988

14. Kida Y, E sposito-Del Puente A, Bogardus C, M ott DM: Insulin resistance is associated with reduced fasting and insulin-stimulated glycogen synthase phosphatase activity in human skeletal muscle. J Clin Invest 85:476-481, 1990

15. Mott DM, Kida Y, Nyomba BL: Human skeletal muscle, type-1 protein phosphatase and insulin resistance. Adv Prot Phosph 7:413-427, 1993

16. Majer M, Mott DM, Mochizuki H, Rowles JC, Pedersen O, Knowler WC, Bogardus $C$, Prochazke $M$ : Association of the glycogen synthase locus on 19q13 with NIDDM in Pima Indians. Di abetologia 39:314-321, 1996

17. Prochazka M, Mochizuki H, Baier LJ , Cohen PTW, Bogardus C: Molecular and linkage analysis of type- 1 protein phosphatase catalytic $\beta$-subunit gene: lack of evidence for its major role in insulin resistance in Pima Indians. Dia betologi a 38:461-466, 1995

18. Hansen L, Hansen T, Vestergaard H, Bjorbaek C, Echwald SM, Clausen J O, Chen $\mathrm{YH}$, Chen MX, Cohen PTW, Pedersen O: A widespread amino acid polymorphism at codon 905 of the glycogen-associated regulatory subunit of protein phosphatase-1 is associated with insulin resistance and hypersecretion of insulin. Hum Mol Genet 4:1313-1320, 1995

19. Hansen L, Reneland R, Hansen T, Berglund L, Rasmussen SK, Busch K, Lishell H, Pedersen 0: Increased insulin stimulated glucose disposal rate in 1161 Caucasian males: interaction between obesity and the Asp905Tyr variant of the glycogen associated subunit of type 1 protein phosphatase (Abstract). Dia betologi a 40 (Suppl. 1):A173, 1997

20. Lillioja S, Mott DM, Spraul M, Ferraro R, Foley JE, Ravussin E, Knowler WC, Bennett $\mathrm{PH}$, Bogardus $\mathrm{C}$ : Insulin resistance and insulin secretory dysfunction as precursors of non-insulin-dependent diabetes mellitus: prospective studies of Pima Indians. N Engl J Med 329:1988-1992, 1993

21. Hingorani AD, Brown MJ : A single molecular assay for the C1166 variant of the angiotensin II type 1 receptor gene. Biochem Biophys Res Com 213:725-729, 1995

22. Shaw $G$, Kamen R: A conserved $A U$ sequence from the $3^{\prime}$ untranslated region of GM-CSF mRNA mediates selective mRNA degradation. Cell 46:659-667, 1986

23. Chen $Y H, H$ ansen $L$, Chen MX, Bjorbaek C, Vestergaard H, Hansen T, Cohen PTW, Pedersen O: Sequence of the human glycogen-associated regulatory subunit of type-1 protein phosphatase and analysis of its coding region and mRNA level in muscle from patients with NIDDM. Di abetes 43:1234-1241, 1994

24. Ross J : mRNA stability in mammalian cells. Mi crobi ol Rev 59:423-450, 1995

25. Hanson RL, Pima Diabetes Gene Group: Genomic scan for markers linked to type II diabetes in Pima Indians (Abstract). Di abetes 46 (Suppl. 1):51A, 1997

26. Knowler WC, Hanson RL, Pima Diabetes Genes Group: Genomic scan for genetic markers linked to diabetes in Pima Indians (Abstract). Di abetologia 40 (Suppl. 1):A8, 1997

27. Chen $C Y$, Shyu AB: Selective degradation of early-response-gene mRNAs: functional analyses of sequence features of the AU-rich elements. Mol Cell Biol 14:8471-8482, 1994

28. Kabnick KS, Housman DE : Determinants that contribute to cyto plasmic stability of human c-fos and $\beta$-globin mRNAs are located at several sites in each mRNA. Mol Cell Biol 8:3244-3250, 1988

29. Gorospe M, Baglioni C: Degradation of unstable interleukin- $1 \alpha$ mRNA in a rabbit reticulocyte cell-free system: Iocalization of an instability determinant to a cluster of AUUUA motifs. J Biol Chem 269:11845-11851, 1994

30. Thompson DB, Pratley R, Ossowski V: Human primary myoblast cell cultures from non-diabetic insulin resistant subjects retain defects in insulin action. J Clin I nvest 98:2346-2350, 1996

31. Ragolia L, Begum N: The effect of modulating the glycogen-associated regulatory subunit of protein phosphatase-1 on insulin action in rat skeletal muscle cells. Endocrinology 138:2398-2404, 1997

32. Sakul H, Pratley R, Cardon L, Ravussin E, Mott DM, Bogardus C: Familiality of physical and metabolic characteristics that predict the development of noninsulin-dependent diabetes mellitus in Pima Indians. Am J Hum Genet 60:651-656, 1997

33. Lillioja S, Bogardus C: Obesity and insulin resistance: lessons learned from the Pima Indians. Diabetes Metab Rev 4:517-540, 1988 